\title{
Congenital Laryngeal Web: A Laryngology Rarity
}

\section{Markandeya Tiwari, Vinson Louis Gonzaga Fernandes, Sarah George, Vibhav B. Sanzgiri, Purva Khandolkar}

Department of Otorhinolaryngology and Head \& Neck Surgery, Goa Medical College and Hospital, Bambolim, Goa, India

Email: fernandesvinson@yahoo.com

How to cite this paper: Tiwari, M., Fernandes, V.L.G., George, S., Sanzgiri, V.B. and Khandolkar, P. (2018) Congenital Laryngeal Web: A Laryngology Rarity. International Journal of Otolaryngology and Head \& Neck Surgery, 7, 143-147. https://doi.org/10.4236/ijohns.2018.74017

Received: May 19, 2018

Accepted: July 2, 2018

Published: July 5, 2018

Copyright $\odot 2018$ by author and Scientific Research Publishing Inc. This work is licensed under the Creative Commons Attribution International License (CC BY 4.0).

http://creativecommons.org/licenses/by/4.0/

\begin{abstract}
Congenital laryngeal web is an otolaryngology rarity, which occurs due to incomplete recanalization of the larynx. We report a case of a 22 year-old patient who presented with a congenital anterior laryngeal web. We shall discuss the presentation, diagnosis, management and postoperative follow up of the case.
\end{abstract}

\section{Keywords}

Laryngeal Web, Larynx, Keel, Silastic Sheet

\section{Introduction}

Among the congenital anomalies of the larynx, laryngeal webs are a rarity. Incomplete recanalization of the laryngotracheal tube is the usual cause. When there is complete failure of recanalization, it results in laryngeal atresia. Laryngeal webs are commonly located anteriorly at the level of the true vocal folds; other sites include the posterior interarytenoid region, subglottic or supraglottic area [1]. Symptoms range from mild dysphonia to airway obstruction, depending on the web size and even stridor in rare cases.

Diagnosis is done by laryngoscopy and management is in the form of laryngoscopic excision of the web using cold instruments or $\mathrm{CO}_{2}$ laser and placement of a silastic keel [2].

The objective of this case report is to frequent ourselves with the presentation, diagnosis, management and postoperative follow up of an otolaryngology rarity of congenital laryngeal web.

\section{Case Report}

A 22 year-old male from Goa, presented to our outpatient department with his- 
tory of hoarseness of voice since childhood, which was insidious in onset and gradually progressive. Owing to his poor socioeconomic status he did not avail of any treatment prior to this and presented now for further evaluation and management. His voice was rough, husky, high pitched and associated with vocal strain and fatigue. He had no difficulty in breathing or respiratory distress. Past history was unremarkable.

General physical examination revealed no abnormalities. On indirect laryngoscopic examination there was an anterior glotic web at the level of the true vocal cords, extending anteroposteriorly from the anterior commissure to the junction of the anterior $2 / 3^{\text {rd }}$ and posterior $1 / 3^{\text {rd }}$ of the true vocal cords. Transversely its extent was from the free margin of one true vocal cord to the other (Figure 1).

It was thick and had a smooth surface, white in colour with overlying streaks of vascularity. Both the vocal cords were mobile. Findings were confirmed on video stroboscopy. Rest of the laryngopharynx was found to be normal. A diagnosis of congenital laryngeal web was made. Routine blood investigations were normal.

Treatment was given in the form of video laryngoscopic excision of the laryngeal web with cold instruments under general anaesthesia followed by placement of a keel (silastic sheet) which was secured with suture material externally (Figure 2). The web tissue was sent for histopathological examination. The patient recovered well post operatively. The keel was left in situ for 6 weeks. Patient was serially followed up every week for 6 weeks. Video stroboscopy examination revealed healthy vocal cord margins and presence of the keel in situ, preventing adhesions, especially at the anterior commissure. The vocal cords were mobile, minimal congestion was noted which gradually subsided at the end of 6 weeks. Patient's voice improved, having less vocal strain and fatigue. After 6 weeks the keel was removed under general anaesthesia and patient recovered well post

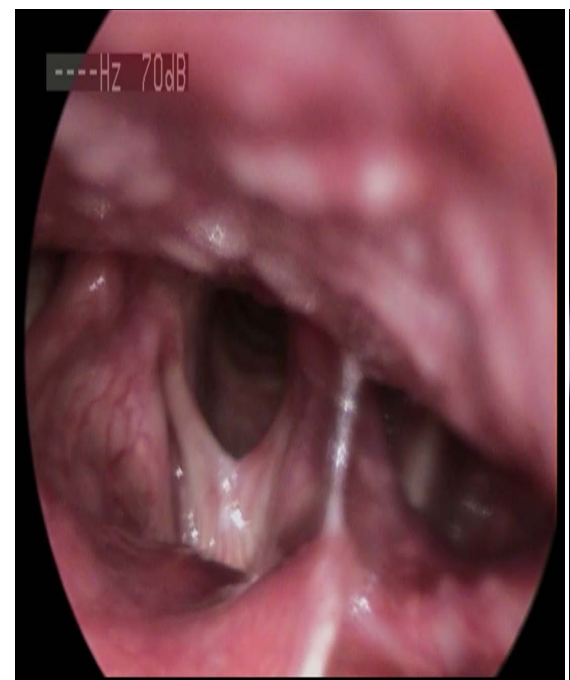

(a)

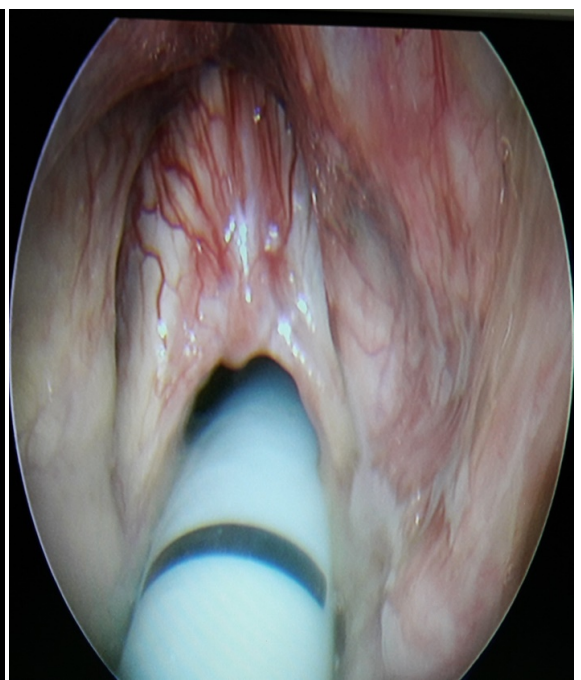

(b)

Figure 1. (a) Laryngeal stroboscopy picture showing the anterior Laryngeal Web; (b) Intra operative Micro laryngoscopy picture showing the web, with endotracheal tube in situ. 


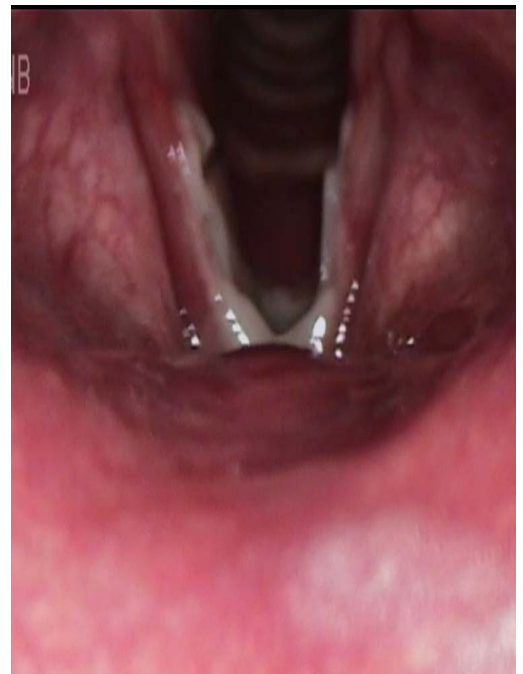

(a)

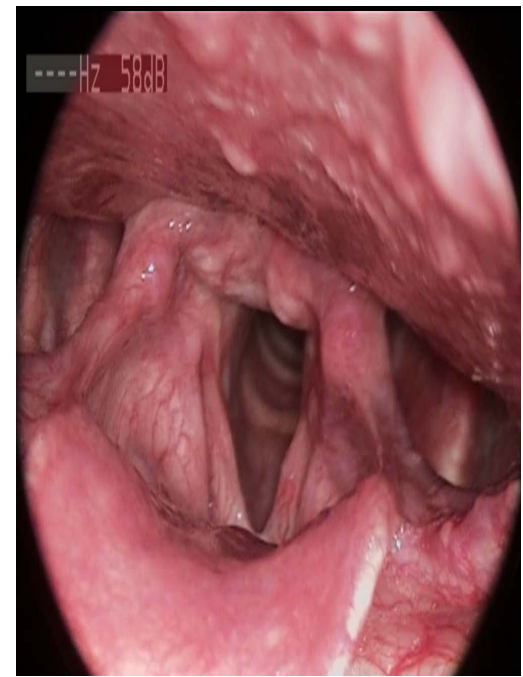

(b)

Figure 2. Laryngeal stroboscopy picture post surgical excision of the Laryngeal web. (a) Post-operative day 7 with keel (Silastic sheet) in situ; (b) 8 weeks post operatively.

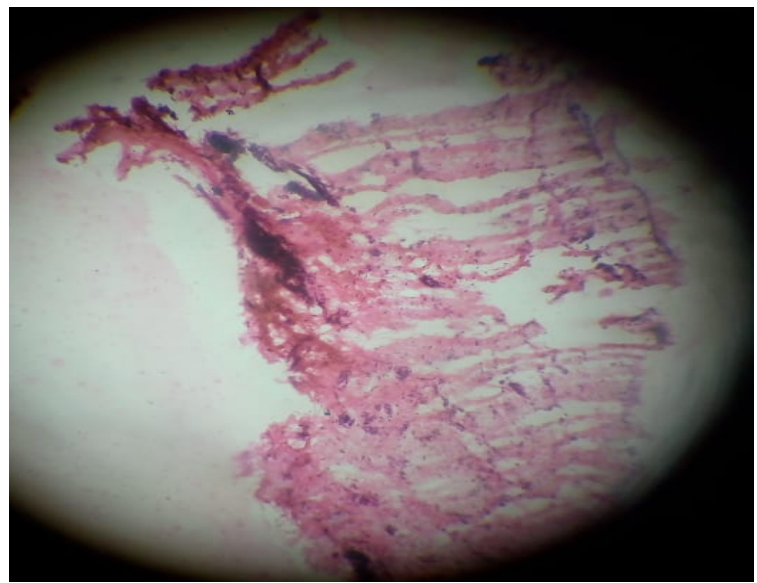

Figure 3. Photomicrograph showing fibrocollagenous tissue with mild hyperplasia and chronic inflammation (H \& E Staining).

operatively.

He was subsequently advised long term vocal hygiene and speech therapy.

Patient's histopathological report revealed fibrous and collagenous tissue with chronic inflammation (Figure 3). He was followed up monthly for over 6 months and had no recurrence. Overall prognosis was good. Patients consent was taken for publishing this case report.

\section{Discussion}

Laryngeal web is a very rare clinical entity. Congenital webs may be associated with various syndromes like Velo cardio facial syndrome, Di-George syndrome etc. In our case the cause of development of the web was a developmental anomaly. $98 \%$ of laryngeal webs are anteriorly located [1].

Based on the degree of airway obstruction they are classified into 4 types [3]. 
Type I: less than $35 \%$ of airway obstruction.

Type II: $35 \%-50 \%$ of airway obstruction.

Type III: $50 \%-75 \%$ of airway obstruction.

Type IV: $75 \%$ - 90\% of airway obstruction.

Our patient had a laryngeal web type III, having marked vocal dysfunction but no airway symptoms.

Clinical presentations of laryngeal webs vary from case to case. Patients may be asymptomatic and may present as unanticipated cases of difficult intubation [1] [4] [5].

Webs in the subglottic region may be occasionally misdiagnosed as cases of bronchial asthma and COPD [4].

Symptoms can vary from hoarseness of voice to respiratory distress, stridor, croup and dysphagia [1].

Asymptomatic patients do not require treatment; others are managed by surgical division. Extensive webs may even require laryngeal reconstruction [3].

Rigid laryngoscopy and bronchoscopy are very necessary to assess the web's site, thickness and vertical and horizontal extension. The web appears as a thin, translucent structure involving the anterior vocal cords or as a thick, fibrous band that extends inferiorly into the sub glottis. The posterior glottis is usually not involved but an interarytenoid web may close it, resulting in limited vocal cord abduction. Posterior webs are best observed when the examination is performed without an endotracheal tube in place.

Radiographic evaluation is helpful in assessing the site and extent of the web and the presence of concurrent congenital subglottic Stenosis [6]. Plain lateral radiographs reveal a characteristic sail sign, which represents persistent tissue between the vocal cords and sub glottis.

Excision of the web results in two opposing surfaces with denuded epithelium which tends to heal together and form a web again. A keel (Silastic sheet) prevents this sequlae. Topical corticosteroid injections and local application of mitomycin C also prevents scarring [7].

\section{Conclusion}

Laryngeal webs range from being asymptomatic to symptomatic. The asymptomatic patients just require regular routine follow up. The symptomatic patients require thorough evaluation radiographically and endoscopically and treatment in the form of surgical excision of the web with the placement of a keel (Silastic sheet) in order to prevent post-operative adhesions.

\section{References}

[1] Chong, Z.K., Jawan, B., Poon, Y.Y. and Lee, J.H. (1997) Unsuspected Difficult Intubation Caused by a Laryngeal Web. British Journal of Anaesthesia, 79, 396-397. https://doi.org/10.1093/bja/79.3.396

[2] Benmansour, N., Remacle, M., Matar, N., Lawson, G., Bachy, V. and Van Der Vorst, S. (2012) Endoscopic Treatment of Anterior Glottic Webs According to the Lich- 
tenberger Technique and Results on 18 Patients. European Archives of Oto-Rhino-Laryngology, 269, 2075-2080.

https://doi.org/10.1007/s00405-012-2001-z

[3] Cummings, C.W. (1986) Otolaryngology-Head and Neck Surgery. CV Mosby, London.

[4] Hodge, G.E. (1930) Congenital Web of the Larynx. Canadian Medical Association Journal, 22, 535-536. [PubMed]

[5] Nguyen, K., et al. (2006) Unexpected Tracheal Web Encountered during Difficult Intubation in the Operating Room. Proceedings (Baylor University. Medical Center), 19, 224-225. [PubMed]

[6] Holinger, L.D. (1994) Histopathology of Congenital Subglottic Stenosis. Annals of Otology, Rhinology and Laryngology, 104, 319-323.

[7] Hartnick, C.J., Hartley, B.E., Lucy, P.D., Liu, J., Bean, J.A., Willging, J.P., et al. (2001) Topical Mitomycin Application after Laryngotracheal Reconstruction: A Randomized Double Blinded, Placebo Controlled Trial. Archives of Otolaryngology-Head and Neck Surgery, 127, 1260-1264.

https://doi.org/10.1001/archotol.127.10.1260 